\title{
Correction to: Temperature self-regulating flat electric heaters based on MWCNTs-modified polymers
}

\author{
Imran Ali ${ }^{1,2} \cdot$ Tahani Saad AIGarni ${ }^{1} \cdot$ Alexandr Shchegolkov $^{3}$. \\ Aleksei Shchegolkov ${ }^{3}$. Sung-Hwan Jang ${ }^{4}$. Evgeny Galunin ${ }^{5} \cdot$ Fadey Komarov $^{6}$. \\ Pavel Borovskikh ${ }^{7}$. Gunel T. Imanova ${ }^{8}$
}

Published online: 23 January 2021

๑) Springer-Verlag GmbH Germany, part of Springer Nature 2021

\section{Correction to: Polymer Bulletin https://doi.org/10.1007/s00289-020-03483-y}

There was a typo error in the second author name.

It is corrected through this correction.

Original article corrected.

The original article can be found online at https://doi.org/10.1007/s00289-020-03483-y.

Imran Ali

drimran.chiral@gmail.com; drimran_ali@yahoo.com

1 Chemistry Department, College of Science, King Saud University, Riyadh 11451, Saudi Arabia

2 Department of Chemistry, Jamia Millia Islamia (Central University), Jamia Nagar, New Delhi, Delhi 110025, India

3 Research Department, Technology and Methods of Nanoproducts Manufacturing, Tambov State Technical University, 1 Leningradskaya Str, Tambov 392036, Russia

4 Department of Civil and Environmental Engineering, Hanyang University ERICA, Ansan, Gyeonggi-do 15588, South Korea

5 Research School of Chemistry and Applied Biomedical Sciences, Tomsk Polytechnic University, 30 Lenina Ave, Tomsk 634050, Russia

6 A.N. Sevchenko Scientific-Research Institute for Applied Physical Problems, Belarusian State University, 7 Kurchatova Str, 220045 Minsk, Republic of Belarus

7 Center for Economics of Materials, Fraunhofer IMW, Friedemann-Bach-Platz 6, Saxony-Anhalt, 06108 Halle (Saale), Germany

8 Department of Physical, Mathematical and Technical Sciences, Institute of Radiation Problems, National Academy of Sciences, Az 1143 Baku, Azerbaijan 
Publisher's Note Springer Nature remains neutral with regard to jurisdictional claims in published maps and institutional affiliations. 